Feedback from a limited number of participants indicated a customised training format was needed to account for low literacy supervisors who do not attend workshops. The project is being modified with a self-paced computer-based training resource that can be used by individuals within their time limitations. This resource will be pilot tested in early 2010 and results will be available in summer 2010 .

\title{
0258 IMPLEMENTATION OF THE SAFETY GUIDELINES FOR HIRED ADOLESCENT FARM WORKERS
}

B C Lee*, R M Fisher, M E Miller Correspondence: National Farm Medicine Center, 1000 North Oak Avenue, 54449, USA

10.1136/ip.2010.029215.258

The North American Guidelines for Childrens Agricultural Tasks (NAGCAT) were released in 1999 as a resource to assist parents in assigning farm jobs to children 7-16 years of age, on family farms. These guidelines have been proven to reduce the risk of agricultural injuries among family farm children by $50 \%$. The NAGCAT were not intended for use in employment situations because they do not incorporate child labour regulations, known as the Hazardous Orders; nor do they reference any other workplace safety and health requirements under OSHA. In 2008 a project was undertaken to address the gap in resources for employers who hire adolescents for agricultural work. The result was the Safety Guidelines for Hired Adolescent Farm Workers (SaGHAF), a series of seven task-specific guidelines to address supervisor responsibilities including knowledge of adolescent characteristics. Training and supervision tips and pertinent federal labour regulations are included. In October 2008 an intervention was undertaken to identify optimal methods to integrate $\mathrm{SaGHAF}$ into field supervisors practices. The initial project focus was to integrate training workshops into existing venues for agricultural employers and field supervisors. 